\title{
Economic vulnerability and unmet healthcare needs among the population aged $50+$ years during the COVID-19 pandemic in Europe
}

\author{
Louis Arnault ${ }^{1} \cdot$ Florence Jusot $^{1,2} \cdot$ Thomas Renaud $^{1}$ (i) \\ Accepted: 21 July 2021 / Published online: 5 September 2021 \\ (c) The Author(s), under exclusive licence to Springer Nature B.V. 2021
}

\begin{abstract}
This study investigated the effect of economic vulnerability on unmet needs during the first wave of the coronavirus disease 2019 (COVID-19) epidemic in Europe among adults aged 50 years and older using data from the regular administration of the Survey of Health, Ageing and Retirement in Europe (SHARE) and the specific telephone survey administered regarding COVID-19 (SHARE Corona Survey). It addressed three main research questions: Did people who were in difficult economic situations before the epidemic face more barriers to accessing healthcare than others? If so, to what extent can these discrepancies be attributed to initial differences in health status, use of care, income or education between vulnerable individuals and non-vulnerable individuals or to differential effects of the pandemic on these groups? Did the effect of economic vulnerability with regard to unmet needs during the pandemic differ across countries? Unmet healthcare needs are characterised by three types of behaviours likely to be induced by the pandemic: forgoing care for fear of contracting COVID-19, having pre-scheduled care postponed and being unable to obtain medical appointments or treatments when needed. Our results substantiate the existence of significant differences in accessing healthcare during the pandemic according to economic vulnerability and of cumulative effects of economic and medical vulnerabilities: the impact of economic vulnerability is notably stronger among those who were in poor health before the outbreak and thus the oldest individuals. The cross-country comparison highlighted heterogeneous effects of economic vulnerability on forgoing care and having care postponed among countries, which are not comparable to the initial cross-country differences in social inequalities in access to healthcare.
\end{abstract}

Keywords COVID-19 $\cdot$ Social inequalities $\cdot$ Healthcare $\cdot$ Unmet needs

\section{Introduction}

The management of the coronavirus 2019 (COVID-19) pandemic has compelled countries to undertake major reorganisations of their healthcare systems, which has led to drastic healthcare rationing. The activities of some health professionals-specialist doctors, dentists and physiotherapists - have been put on hold, and programmed care has been rescheduled (WHO, 2020; Søreide et al., 2020). In

Responsible Editor: Matthias Kliegel.

Thomas Renaud

thomas.renaud@dauphine.psl.eu

1 LEDA, CNRS, IRD, Université Paris-Dauphine, Université PSL, Paris, France

2 IRDES (Institut de Recherche et Documentation en Economie de la Santé), Paris, France the meantime, the demand for care may also have changed. Shortages in the supply of healthcare and travel restrictions may have increased transport and transaction costs incurred by accessing healthcare. Some people may also have forgone care for fear of contracting COVID-19; this fear is potentially stronger in the population at risk for severe COVID-19, such as elderly and chronically ill individuals, and is exacerbated by difficulties in obtaining and processing relevant health information.

A substantial decrease in the amount of emergency and scheduled care provided has been observed in most countries. In the USA, Chatterji and Li (2020) reported a 67\% reduction in outpatient visits during the third week of April 2020 compared to a baseline pre-epidemic week and a $25 \%$ reduction by mid-May. A dramatic decrease in the provision of healthcare has also been observed with regard to primary care visits, visits to emergency departments and elective surgeries (Hartnett et al. 2020; Mehrotra et al. 2020), 
which seems to be causally linked to "stay-at-home" and non-essential business closure policies (Ziedan et al. 2020). In France, ambulatory care expenditures decreased by $12 \%$ during the lockdown compared to the same period the year before (CNAMTS 2020). England has seen a sharp decrease of 57\% in visits to emergency departments in April-May compared to the year before, followed by a gradual upturn thereafter (NHS 2020). In Belgium, 75\% of the population reported having forgone planned healthcare since the outbreak (Bertier et al. 2021). On average, European countries have suffered a partial or complete disruption in the provision of $40 \%$ of essential health services in hospitals, primarily preventive, emergency and oncological care (WHO, 2020). Elective surgery was notably affected: more than 2 million surgical procedures per week were cancelled or postponed worldwide during the peak weeks of disruption (Negopdiev et al. 2020).

It is therefore important to identify which populations have suffered most from these disruptions in healthcare provision, as these are likely to have major long-term effects on the health of these populations. Preliminary studies have established that delays in diagnosis and treatment in the UK could lead to a $5 \%$ to $15 \%$ increase in the number of deaths from cancer up to 5 years after diagnosis (Maringe et al. 2020). Given the magnitude of pre-existing health-related inequalities, and in particular the pre-existing difficulties of the most deprived in accessing healthcare, their ability to meet their healthcare needs during the pandemic must be addressed. Ensuring health equity, and especially guaranteeing access to healthcare to the poorest, is one of the major public health objectives in Europe (Marmot and Bell 2016). It is therefore crucial to determine to what extent the COVID-19 pandemic stands as a potentially serious obstacle to achieving this goal (Marmot et al. 2020).

Evidence of social inequalities in healthcare use, i.e. disparities in the utilisation of healthcare for the same health need depending on the socio-economic level, has been extensively described in European countries, particularly regarding visits to specialists and dentists, preventive care and the risk of forgoing care due to costs, distance or waiting time (OECD 2019), especially among older adults (Jürges and Stella 2019; Litwin and Sapir 2009). There are multiple channels through which pandemics and situations of care rationing can reinforce these inequalities in healthcare consumption at the expense of the poorest. First, as described by Andersen in his review of the behavioural model of health services (Andersen 1995), inequalities in access due to differences in social structure (e.g. education, social stratification), health beliefs (attitudes, values and knowledge about health and health services) or enabling resources (e.g. income, health insurance and availability of health providers) may have increased. The most socially vulnerable people and those most "disconnected" from the healthcare system may have been isolated even more than usual. The pandemic may also have modified people's demand for healthcare in distinctive manners depending on their social status. For example, fear of contracting COVID-19 may differ socially due to differences in exposure to the virus at home or at work, differences in the likelihood of developing severe COVID-19 related to differences in the prevalence of chronic diseases and heterogeneity in risk perception and risk aversion. The pandemic has caused decreases in income and an increase in poverty situations and may have modified the expenses that individuals have had to face. Finally, the rationing of supply may have led to a change in the price structure of the available care.

We might observe a specific effect of the respondent's economic vulnerability - which refers to his/her real budgetary constraint, i.e. the difference between income and expenses and his/her ability to withstand unexpected financial shocks-on unmet healthcare needs. Després et al. (2011a) show that decisions to forgo care for monetary reasons are related not only to the actual income level but also to disposable income and exceptional health expenses. In a parallel publication, they built a deprivation score accounting for people's real level of budgetary constraints, regardless of their income, as well as their financial insecurity (Després et al. 2011b). More than actual income, the deprivation score proved to be the most significant predictor of forgoing care for monetary reasons. Similarly, in these times of great uncertainty due to the epidemic context, economic vulnerability and the consequent feeling of financial insecurity might have important effects on how to cope with other events, notably health events, in budgetary trade-offs.

Conversely, health systems may have adopted a general policy of healthcare resource prioritisation in favour of people with the highest need, especially older people with comorbidities, irrespective of any other characteristic (Hanna et al. 2020; Pikoulis et al. 2020; Rosenbaum 2020). The rationing of planned and specialist care may also have had a lower impact on those who usually make less use of these types of care, especially the more socio-economically disadvantaged (Devaux 2015; OECD 2019; van Doorslaer et al. 2004). Given the differences in the organisation of healthcare systems, responses to the pandemic and initial levels of inequalities in healthcare utilisation across countries, it seems appropriate to assess the between-country variations in the effect of economic vulnerability on unmet healthcare needs during the first epidemic wave.

To date, only a few studies have analysed social disparities in the likelihood of unmet care needs specific to the COVID-19 pandemic, mainly for the USA. Gonzalez et al. (2020) found a clear effect of social deprivation on unmet needs: the probability of avoiding getting care due to concerns about exposure to the virus was $36 \%$ for the people who lost their job or work-related income during the 
pandemic and only $25 \%$ for those who did not. Racial and ethnic inequities in access to dental care during the pandemic have also been observed (Kranz et al. 2021). Another study revealed that delaying or avoiding obtaining urgent medical care due to concerns about COVID-19 was more common among less educated and usually underprivileged ethnic groups, although no difference was observed after stratification by income level (Czeisler et al. 2020). Similarly, from UK data, no income inequality was established in unmet inpatient and outpatient care needs: only transitory inequalities in favour of the richest in the use of general practitioner (GP) consultations were observed at the peak of the first wave. The only persisting pro-rich inequalities identified are for services that are highly correlated with people's ability to pay, such as over-the-counter medicines (Davillas and Jones 2021).

This study investigated the effect of economic vulnerability on unmet needs-forgoing care due to the fear of contracting COVID-19, postponing scheduled care and facing the inability to obtain a medical appointment or treatment-during the first wave of the COVID-19 epidemic in 26 European countries participating in the Survey of Health, Ageing and Retirement in Europe (SHARE). It addresses the following questions: Did people in difficult economic situations before the epidemic face more barriers to accessing healthcare than others? If so, to what extent can these discrepancies be attributed to initial differences in health status, use of care, income or education between vulnerable and non-vulnerable individuals or to differential effects of the pandemic on these specific groups? Did the impact of economic vulnerability during the pandemic differ across countries?

\section{Data and methods}

\section{Sample selection}

This research is based on SHARE panel data (Börsch-Supan et al. 2013). The population to be analysed consists of a subsample of longitudinal SHARE respondents who have taken part in two separate SHARE collection operations: i) the eighth wave of the regular face-to-face SHARE survey, which started in October 2019 and stopped abruptly in March 2020 due to the outbreak of Corona with a completion rate of $67 \%$ only, and ii) the SHARE Corona survey, an ad hoc phone survey focused on the impact of the COVID19 crisis, conducted in June-July 2020 among SHARE panel households and to which $71 \%$ of them agreed to participate (Scherpenzeel et al. 2020; Sand 2021).

The sample was restricted to participants aged 50 years and over living in private households who participated in both the regular face-to-face Wave 8 and SHARE Corona Survey and for whom there were no missing values for any of the variables involved in the analyses. In the end, the sample included 31,819 respondents.

\section{Measuring unmet healthcare needs during the first wave of the epidemic}

Access to care is here identified by the subjective assessment of unmet needs due to barriers to healthcare, which have been shown to be associated with the subsequent deterioration of health status and thus to provide relevant information to guide policy action (Allin et al. 2010; Dourgnon et al. 2012; Ko 2016). Subjective unmet needs can be defined as the gap between the amount of healthcare received by an individual and the amount of healthcare he/she desires based on his/her needs and preferences with regard to health and healthcare. Consequently, forgoing care may be more common among those with a higher demand for health services for a given healthcare need, particularly among the more affluent (Devaux 2015; OECD, 2019; van Doorslaer et al. 2004).

Dimensions of unmet healthcare needs are captured by the SHARE Corona Survey through the assessment of three different kinds of barriers to accessing health services that have emerged since the start of the epidemic for various reasons: 1) forgoing healthcare due to the fear of contracting COVID-19 (fear): "Since the outbreak of Corona, did you forgo medical treatment because you were afraid to become infected by the coronavirus?"; 2) having planned healthcare cancelled or rescheduled (postponement): "Did you have a medical appointment scheduled, which the doctor or medical facility decided to postpone due to Corona?"; and 3) being unable to obtain a medical appointment (unavailability): "Did you ask for an appointment for a medical treatment since the outbreak of Corona and did not get one?".

It is worth analysing these three indicators separately insofar as they presumably reflect different reasons for not accessing healthcare and different types of unmet needs. The decision to forgo care for fear of contracting COVID-19 can a priori apply to any type of care. However, postponement implies that accessing healthcare was originally scheduled-an appointment with a specialist, a planned medical exam, an elective surgery, etc.- -and therefore might be more common in people with poor health and chronic conditions. Impossibility of obtaining a medical appointment is instead associated with a request for more immediate medical care, which is usually provided by first-line health professionals in response to acute health problems.

\section{Measuring economic vulnerability prior to the outbreak}

Economic vulnerability before the outbreak is assessed based on the self-reported difficulty of "making ends meet" 
in SHARE Wave 8, which is collected in the following question: "Thinking of your household's total monthly income, would you say that your household is able to make ends meet...? With great difficulty/with some difficulty/fairly easily/easily". Respondents who express some or great difficulty are said to be economically vulnerable.

This question originates from pioneering works on the various dimensions and measures of poverty (Goedhart et al. 1977) and has the advantage of providing a synthetic and subjective measure of living conditions, comparable in principle between countries regardless of cultural norms (Fahey 2007). More than the actual income, this variable should measure the respondent's real budgetary constraint-i.e. the difference between the ability to pay and expensesand his/her ability to withstand unexpected financial shocks. As a result, because of its subjective nature, this variable is expected to be more strongly correlated with the consequent feeling of financial insecurity and therefore has significant effects on the trade-offs made following the epidemic outbreak.

To capture this pure effect of self-perceived economic vulnerability, additional measures of education and income are controlled for in the analyses. Education is measured on three aggregate levels of the International Standard Classification of Education (ISCED-1997): lower secondary or under, upper secondary, post-secondary and tertiary education. The income variable considered here is the monthly total net household income, expressed in equivalised value by using the modified Organisation for Economic Co-operation and Development (OECD) equivalence scale to account for household size. No imputation of income is applied. Ultimately, respondents are classified into their income quartile based on the income distribution of their country in the SHARE sample.

\section{Measuring levels of healthcare needs and utilisation prior to the outbreak}

Investigating the effect on economic vulnerability on unmet needs during the pandemic requires disentangling the influence of economic vulnerability per se from the confounding effects due to initial differences in baseline health status and healthcare utilisation between social groups.

Two different sets of measures were then used.

First, we sought to characterise individuals with serious chronic conditions, differentiating between diseases identified in the medical literature as putting people at higher risk for developing severe COVID-19 (Williamson et al. 2020; Zheng et al. 2020; Zhou et al. 2020), who may have been more likely to have forgone care for fear of contracting COVID-19, and other chronic diseases. In SHARE, lists of chronic conditions and drug treatments taken at least once a week are provided to respondents. Respondents were defined as having a chronic condition that increases the risk of severe COVID-19 when they reported that they had been diagnosed with or were taking medication for any of the following diseases: chronic heart, lung or kidney disease; cerebrovascular disease (including stroke); cancer; hypertension; and diabetes.

Obesity also increases the risk of developing severe COVID-19. In our analysis, an individual was considered obese when his/her body mass index (BMI) was greater than or equal to $30 \mathrm{~kg} / \mathrm{m}^{2}$.

In addition, self-reported health was included among the variables assessing baseline health needs, and it was grouped into four categories ("excellent/very good", "good", "fair" and "poor"). Despite its inherent subjectivity, this variable has been shown to be a good proxy for global health status, as well as a reliable predictor of all-cause mortality (Idler and Benyamini 1997) and of the level of healthcare use (DeSalvo et al. 2005).

Differences in the use of health services before the outbreak were captured through three additional variables: the number of encounters with a general practitioner and with a specialist during the previous 12 months, and whether respondents had visited a dentist at least once in the same time frame. The introduction of healthcare utilisation at baseline into the models is particularly needed in the analysis of postponed care because only care that was planned before the pandemic could have been postponed.

\section{Empirical strategy}

The empirical strategy involved a sequence of three probit models that were successively estimated for the three types of unmet needs during the first wave of the epidemic.

As a first step, the overall influence of economic vulnerability on outcomes was estimated after controlling for differences in unmet needs due to age, sex, relationship status (living alone or not) and country of residence. This also enabled us to identify whether older individuals suffered more from unmet needs than others, irrespective of their economic vulnerability status. In the second step, we investigated how the overall effect of economic vulnerability evolved when baseline differences in healthcare needs and utilisation were accounted for. The third step additionally included the education level and the income quartile of the respondents as covariates: the objective here was to capture the pure effect of self-perceived economic insecurity, as our measure better reflected the extent of the strain on the respondent's budget once adjusted for the objective level of income and education as indicators of social status and skills.

For all three outcomes, the full model specification was re-estimated separately for each country to explore the heterogeneity of the effects of economic vulnerability on unmet needs across European countries. Some categories of the age 
group, self-assessed health, GP visits and specialist visits variables were grouped together, and the obesity indicator was dropped so that each model could be re-estimated with the same set of covariates in all countries despite the smaller subsample sizes. Only two specifications could not be reestimated on the subsample of respondents from Bulgaria due to the very low share of individuals concerned by care postponement or unavailability (see Table 2).

Finally, for each type of unmet need, the full model was re-estimated over the entire sample with the addition of an interaction term between economic vulnerability and baseline self-reported health. This interaction model reveals to what extent the effect of economic vulnerability on unmet needs differed between originally healthy and unhealthy individuals.

\section{Results}

Table 1 provides a description of the sample's average characteristics. Country-specific weights were applied to ensure that the country subsamples were representative of the national populations aged 50 years and over with regard to age, sex and region (De Luca and Rossetti 2018). The mean age of our sample was 66.3 years, and $48 \%$ of the respondents were aged 65 years or older. Women represented 54\% of the respondents.

\section{Descriptive statistics}

Unmet healthcare needs during the period were mainly revealed by the postponement of planned care (25\%) and, to a lesser extent, by situations in which people forwent care for fear of contracting COVID-19 (12\%) or were unable to obtain a medical appointment (5\%) (Table 1). The proportion of respondents who reported they experienced a postponement of at least one planned medical encounter was notably high in several countries (Table 2), such as Luxembourg (54\%), the Czech Republic (37\%), France (36\%) and Belgium (35\%). The variability between countries in forgoing care for fear of contracting COVID-19 was lower and only weakly correlated with the intensity of the first wave of the epidemic: the proportions of Germans (17\%) and Swedes (15\%) who have forgone care for fear of COVID-19 were higher than the proportions observed in countries where the impact of the epidemic has been greater, such as France (10\%) and Spain (3\%). The proportion of individuals who were unable to obtain a medical appointment differed across countries as well, reaching $10 \%$ in France and $12 \%$ in Latvia. In particular, it was clearly established by Smolić et al. (2021) that countries of "Old" Europe-with higher universal health coverage and stricter containment and closure policies during the pandemicwere more likely to have medical services postponed. These heterogeneous proportions across countries justify the adjustment of all models for country fixed effects.

Table 1 provides additional insights. Eighty-three per cent of individuals aged 50 years and over reported suffering from a chronic condition or taking regular medical treatments for such a condition in the interview conducted before the pandemic. This proportion was only 59\% when the scope was narrowed to only those chronic diseases predisposing patients to severe COVID-19. Regarding healthcare utilisation, respondents reported an average of 4.1 contacts with general practitioners and 2.7 contacts with specialists during the 12 months before the interview. Additionally, an average of $57 \%$ of those people consulted a dentist at least once in the same period.

Thirty-six per cent of the respondents admitted experiencing difficulties in making ends meet on their household income and were therefore considered economically vulnerable. Older individuals were significantly less economically vulnerable than younger seniors, whereas women were significantly more economically vulnerable than men.

Economically vulnerable people had lower levels of education and income than others on average, with almost one in two having only primary or lower secondary education (compared to $27 \%$ among others) and $32 \%$ belonging to the first income quartile (compared to $11 \%$ among others). Nonetheless, economic vulnerability also concerns individuals with higher incomes, since almost $30 \%$ of economically vulnerable individuals have an income that is above the median, and $12 \%$ of them have an income above the $3^{\text {rd }}$ quartile. Economically vulnerable people were also in worse health than others. As a result, without adjustment for age or health status, they made more frequent use of primary care, visiting their general practitioner an average of 4.9 times a year, compared to 3.6 times in the non-vulnerable population. This difference in healthcare utilisation was negligible for specialist doctors and was reversed for dentists, reflecting the unaffordability of dental care for the lowest socioeconomic groups.

Without adjustment for differences in other characteristics between the two subpopulations, people who were economically vulnerable at baseline were less likely to have had at least one medical treatment postponed during the first wave of the pandemic (22\% versus $26 \%$ ) and were as likely to have been unable to obtain a medical appointment (6\% versus $5 \%$ ). No difference according to economic vulnerability was observed in the probability of having forgone care for fear of contracting COVID-19.

\section{Overall impact of economic vulnerability on unmet needs}

Table 3 shows the results of the three steps of probit models estimated for each of the three indicators of unmet needs. 
Table 1 Sample description, baseline healthcare needs and utilisation, and unmet needs during the first wave of the epidemic stratified by economic vulnerability

\begin{tabular}{|c|c|c|c|c|}
\hline & All respondents & $\begin{array}{l}\text { Not economically vulnerable } \\
\text { (individuals WITHOUT dif- } \\
\text { ficulties in making ends meet) }\end{array}$ & $\begin{array}{l}\text { Economically vulnerable } \\
\text { (individuals WITH difficulties } \\
\text { in making ends meet) }\end{array}$ & $\begin{array}{l}\text { Statistical significance of the } \\
\text { difference between eco- } \\
\text { nomically vulnerable and not } \\
\text { vulnerable }\end{array}$ \\
\hline $\mathrm{N}$ & 31,819 & 19,364 & 12,455 & \\
\hline Weighted N (in million) & 170.8 & 109.4 & 61.4 & \\
\hline \multicolumn{5}{|c|}{ Unmet healthcare needs during the first epidemic wave } \\
\hline $\begin{array}{l}\text { Forgoing medical care } \\
\text { because of the fear of con- } \\
\text { tracting COVID-19 }(\%)\end{array}$ & 12 & 12 & 12 & NS \\
\hline $\begin{array}{l}\text { Planned care postponed by the } \\
\text { healthcare provider }(\%)\end{array}$ & 25 & 26 & 22 & $* * *$ \\
\hline $\begin{array}{l}\text { Impossibility of obtaining } \\
\text { medical appointment/treat- } \\
\text { ment }(\%)\end{array}$ & 5 & 5 & 6 & $* *$ \\
\hline \multicolumn{5}{|c|}{ Main characteristics before outbreak } \\
\hline Age (mean) & 66.3 & 66.6 & 65.8 & $* * *$ \\
\hline Aged 65 years or older $(\%)$ & 48 & 50 & 45 & $* * *$ \\
\hline Women $(\%)$ & 54 & 52 & 56 & $* *$ \\
\hline In a relationship (\%) & 64 & 67 & 60 & $* * *$ \\
\hline $\begin{array}{l}\text { Employed, among those aged } \\
50-64 \text { years }(\%)\end{array}$ & 62 & 71 & 47 & $* * *$ \\
\hline $\begin{array}{l}\text { (Pre-)primary or lower sec- } \\
\text { ondary education }(\%)\end{array}$ & 35 & 27 & 49 & $* * *$ \\
\hline Upper secondary education (\%) & 39 & 40 & 37 & $* *$ \\
\hline $\begin{array}{l}\text { Post-secondary or tertiary } \\
\text { education }(\%)\end{array}$ & 26 & 33 & 14 & $* * *$ \\
\hline Income quartile: <Q1 (\%) & 19 & 11 & 32 & $* * *$ \\
\hline Income quartile: [Q1; Q2[ (\%) & 21 & 20 & 24 & $* * *$ \\
\hline Income quartile: [Q2; Q3[ (\%) & 23 & 26 & 17 & $* * *$ \\
\hline Income quartile: $\geq$ Q3 (\%) & 23 & 29 & 12 & $* * *$ \\
\hline Economic vulnerability (\%) & 36 & & & \\
\hline \multicolumn{5}{|c|}{ Health status and healthcare utilisation before outbreak } \\
\hline $\begin{array}{l}\text { Diagnosed with a chronic } \\
\text { condition or regular medica- } \\
\text { tion }(\%)\end{array}$ & 83 & 82 & 85 & $*$ \\
\hline $\begin{array}{l}\text { Chronic condition linked with } \\
\text { severe COVID-19 }(\%)\end{array}$ & 59 & 56 & 65 & $* * *$ \\
\hline $\begin{array}{l}\text { Obesity: body mass index } \\
(\mathrm{BMI}) \geq 30(\%)\end{array}$ & 23 & 20 & 26 & $* * *$ \\
\hline $\begin{array}{l}\text { Self-assessed health: fair or } \\
\text { poor }(\%)\end{array}$ & 37 & 30 & 49 & $* * *$ \\
\hline $\begin{array}{l}\text { Number of contacts with a GP } \\
\text { in the last } 12 \text { months (mean) }\end{array}$ & 4.1 & 3.6 & 4.9 & $* * *$ \\
\hline $\begin{array}{l}\text { Number of contacts with } \\
\text { a specialist in the last } \\
12 \text { months (mean) }\end{array}$ & 2.7 & 2.6 & 2.8 & NS \\
\hline $\begin{array}{l}\text { Visited a dentist in the last } \\
12 \text { months (\%) }\end{array}$ & 57 & 68 & 37 & $* * *$ \\
\hline
\end{tabular}

Data: Preliminary SHARE wave 8 release 0 . Conclusions are preliminary. Sample: $N=31,819$ respondents in 26 countries

Weighted frequencies; Student's t-tests were performed to test the equality of means for continuous variables, and Pearson's Chi-squared tests were performed for binary variables; $* p$-value $<0.1 * * p$-value $<0.05 * * * p$-value $<0.01$, NS: no significant difference 
Table 2 Unmet healthcare needs during the first wave of the epidemic by country

\begin{tabular}{|c|c|c|c|}
\hline & $\begin{array}{l}\text { Forgoing medical care because of } \\
\text { the fear of COVID-19 }(\%)\end{array}$ & $\begin{array}{l}\text { Planned care } \\
\text { postponed }(\%)\end{array}$ & $\begin{array}{l}\text { Impossibility of obtaining } \\
\text { medical appointment/treat- } \\
\text { ment }(\%)\end{array}$ \\
\hline All countries & 12 & 25 & 5 \\
\hline Germany & 17 & 19 & 3 \\
\hline Sweden & 15 & 18 & 4 \\
\hline The Netherlands & 5 & 29 & 3 \\
\hline Spain & 3 & 25 & 4 \\
\hline Italy & 17 & 26 & 7 \\
\hline France & 10 & 36 & 10 \\
\hline Denmark & 10 & 31 & 4 \\
\hline Greece & 16 & 11 & 5 \\
\hline Switzerland & 14 & 28 & 3 \\
\hline Belgium & 13 & 35 & 9 \\
\hline Israel & 27 & 24 & 9 \\
\hline Czech Republic & 19 & 37 & 3 \\
\hline Poland & 9 & 28 & 6 \\
\hline Luxemburg & 23 & 54 & 7 \\
\hline Hungary & 6 & 22 & 4 \\
\hline Slovenia & 4 & 33 & 3 \\
\hline Estonia & 10 & 24 & 8 \\
\hline Croatia & 9 & 23 & 3 \\
\hline Lithuania & 14 & 28 & 12 \\
\hline Bulgaria & 10 & 1 & 1 \\
\hline Cyprus & 11 & 15 & 4 \\
\hline Finland & 8 & 19 & 5 \\
\hline Latvia & 13 & 14 & 5 \\
\hline Malta & 11 & 36 & 3 \\
\hline Romania & 6 & 8 & 6 \\
\hline Slovakia & 15 & 20 & 5 \\
\hline
\end{tabular}

Data: Preliminary SHARE wave 8 release 0 . Conclusions are preliminary.

Sample: $N=31,819$ respondents in 26 countries

Weighted frequencies
After controlling for differences in age, sex, relationship status and country (step 1), comparatively more of the most economically vulnerable people reported having forgone medical care because of the fear of COVID-19 $(+1.8$ percentage points) and not being able to obtain a medical appointment when needed ( +1.3 points). No significant difference between vulnerable and non-vulnerable individuals was observed in the probability of experiencing a postponement of scheduled care. In addition, people aged 65 to 85 years were significantly more likely than others to have had unmet needs during the epidemic, especially with regard to forgoing care due to fear of COVID-19 and experiencing the postponement of care, with an increasing risk with increasing age until the age of 79 years.

As expected, when introduced into the models (step 2), all the variables related to the need for healthcare, except obesity, were positively correlated with each of the three types of unmet needs. A self-reported global health status of "poor" rather than "excellent or very good" increased the probability of having forgone care for fear of contracting COVID- 19 by 4.4 percentage points, the risk of postponement of care by 4.0 points and the probability of having been unable to obtain a medical appointment by 2.0 points.

It also appears that unmet needs have been even more pronounced among individuals suffering from chronic conditions that are not specifically associated with an increased risk of severe forms of COVID-19: patients with non-specific chronic conditions were more likely than patients with chronic conditions that predisposed them to severe COVID19 to have refrained from healthcare ( +3.1 points compared with +1.0 points), to have experienced the postponement of scheduled care $(+4.5$ versus +4.0$)$ and to have been unable to obtain a medical appointment $(+1.2$ versus +0.3$)$. The pre-epidemic intensity of healthcare utilisation was also 
Table 3 Effects on the probability of unmet healthcare needs during the first wave of the epidemic

\begin{tabular}{|c|c|c|c|c|c|c|c|c|c|}
\hline & \multicolumn{3}{|c|}{$\begin{array}{l}\text { Forgoing medical care because of the fear } \\
\text { of COVID-19 }\end{array}$} & \multicolumn{3}{|c|}{ Planned care postponed } & \multicolumn{3}{|c|}{$\begin{array}{l}\text { Impossibility of obtaining medical appoint- } \\
\text { ment / treatment }\end{array}$} \\
\hline & Step 1 & Step 2 & Step 3 & Step 1 & Step 2 & Step 3 & Step 1 & Step 2 & Step 3 \\
\hline Age: 65-69 (Ref. 50-64) & $0.011 * *$ & 0.003 & 0.004 & $0.012 *$ & -0.005 & -0.003 & 0.001 & -0.002 & -0.002 \\
\hline Age: $70-74$ (Ref. 50-64) & $0.016^{* * *}$ & 0.003 & 0.005 & $0.015^{* *}$ & $-0.014^{* *}$ & $-0.012^{*}$ & -0.002 & $-0.008^{* *}$ & $-0.008^{* *}$ \\
\hline Age: $75-79$ (Ref. 50-64) & $0.015 * *$ & -0.004 & 0 & $0.024 * * *$ & $-0.015^{*}$ & -0.011 & -0.002 & $-0.010^{* *}$ & $-0.010^{* *}$ \\
\hline Age: 80-84 (Ref. 50-64) & $0.023 * * *$ & 0.002 & 0.006 & -0.008 & $-0.046 * * *$ & $-0.041 * * *$ & -0.002 & $-0.010 * *$ & $-0.010 * *$ \\
\hline Age: $85+($ Ref. 50-64) & -0.009 & $-0.027 * * *$ & $-0.022 * * *$ & $-0.057 * * *$ & $-0.080 * * *$ & $-0.073^{* * *}$ & $-0.014 * * *$ & $-0.020 * * *$ & $-0.021 * * *$ \\
\hline Women & $0.046^{* * *}$ & $0.041 * * *$ & $0.042 * * *$ & $0.030 * * *$ & $0.020^{* * *} *$ & $0.023 * * *$ & $0.005^{*}$ & 0.003 & 0.002 \\
\hline In a relationship & 0.003 & 0.001 & 0.001 & 0.005 & -0.001 & -0.001 & 0.001 & 0.001 & 0.001 \\
\hline Economic vulnerability & $0.018 * * *$ & $0.010 * *$ & $0.015 * * *$ & 0.006 & -0.006 & -0.002 & $0.013 * * *$ & $0.009 * * *$ & $0.007 * *$ \\
\hline $\begin{array}{l}\text { Primary education (Ref. } \\
\text { Post- secondary) }\end{array}$ & & & $-0.031 * * *$ & & & $-0.037 * * *$ & & & -0.003 \\
\hline $\begin{array}{l}\text { Secondary education (Ref. } \\
\text { Post- secondary) }\end{array}$ & & & $-0.021 * * *$ & & & $-0.012^{*}$ & & & -0.003 \\
\hline $\begin{array}{l}\text { Income quartile: }<\mathrm{Q} 1 \\
\quad(\text { Ref. } \geq \mathrm{Q} 3)\end{array}$ & & & -0.005 & & & -0.008 & & & $0.008^{*}$ \\
\hline $\begin{array}{l}\text { Income quartile: [Q1; Q2[ } \\
\quad(\text { Ref. } \geq \mathrm{Q} 3)\end{array}$ & & & $-0.013^{* *}$ & & & -0.002 & & & 0.005 \\
\hline $\begin{array}{l}\text { Income quartile: [Q2; Q3[ } \\
\quad(\text { Ref. } \geq \mathrm{Q} 3)\end{array}$ & & & 0 & & & -0.004 & & & 0.002 \\
\hline $\begin{array}{l}\text { Income quartile: Missing } \\
\quad(\text { Ref. } \geq \text { Q3) }\end{array}$ & & & -0.004 & & & $-0.019^{* *}$ & & & 0.006 \\
\hline $\begin{array}{l}\text { 1+ chronic condition } \\
\text { linked with severe } \\
\text { COVID-19 }\end{array}$ & & $0.010^{* *}$ & $0.011 * *$ & & $0.041 * * *$ & $0.042 * * *$ & & 0.003 & 0.003 \\
\hline $1+$ other chronic condition & & $0.031 * * *$ & $0.032 * * *$ & & $0.045^{* * *}$ & $0.045^{* * *}$ & & $0.012 * * *$ & $0.012 * * *$ \\
\hline $\mathrm{BMI} \geq 30$ & & 0.004 & 0.005 & & 0.002 & 0.003 & & 0.001 & 0.001 \\
\hline $\begin{array}{l}\text { Self- assessed health: } \\
\text { Excellent or very good } \\
\text { (Ref. good) }\end{array}$ & & $-0.018^{* * *}$ & $-0.020^{* * *}$ & & $-0.012^{*}$ & $-0.014^{* *}$ & & $-0.006^{*}$ & $-0.006^{*}$ \\
\hline $\begin{array}{l}\text { Self- assessed health: fair } \\
\text { (Ref. good) }\end{array}$ & & $0.021 * * *$ & $0.023 * * *$ & & $0.027 * * *$ & $0.029 * * *$ & & $0.007 * *$ & $0.007 * *$ \\
\hline $\begin{array}{l}\text { Self- assessed health: } \\
\text { poor (Ref. good) }\end{array}$ & & $0.026 * * *$ & $0.029 * * *$ & & $0.028 * * *$ & $0.033 * * *$ & & $0.014 * * *$ & $0.014 * * *$ \\
\hline $\begin{array}{l}\text { Contacts with a GP: } 1 \text { or } 2 \\
\text { (Ref. O) }\end{array}$ & & 0.006 & 0.006 & & $0.051 * * *$ & $0.051 * * *$ & & $0.008^{* *}$ & $0.008 * *$ \\
\hline $\begin{array}{l}\text { Contacts with a GP: } 3 \text { to } 5 \\
\text { (Ref. O) }\end{array}$ & & $0.013 * *$ & $0.014 * *$ & & $0.048 * * *$ & $0.048 * * *$ & & $0.008^{*}$ & $0.008^{*}$ \\
\hline $\begin{array}{l}\text { Contacts with a GP: } \\
6+(\text { Ref. } 0)\end{array}$ & & 0.011 & $0.012^{*}$ & & $0.059 * * *$ & $0.059 * * *$ & & $0.013 * * *$ & $0.013 * * *$ \\
\hline $\begin{array}{l}\text { Contacts with a specialist: } \\
1 \text { or } 2(\text { Ref. } 0)\end{array}$ & & $0.036^{* * * *}$ & $0.034 * * *$ & & $0.085^{* * *}$ & $0.083^{* * *}$ & & $0.013 * * *$ & $0.014 * * *$ \\
\hline $\begin{array}{l}\text { Contacts with a specialist: } \\
3 \text { to }-5(\text { Ref. O) }\end{array}$ & & $0.049 * * *$ & $0.046 * * *$ & & $0.146^{* * *}$ & $0.144 * * *$ & & $0.022 * * *$ & $0.022 * * *$ \\
\hline $\begin{array}{l}\text { Contacts with a specialist: } \\
6+(\text { Ref. } 0)\end{array}$ & & $0.054 * * *$ & $0.050 * * *$ & & $0.188^{* * *}$ & $0.184 * * *$ & & $0.035 * * *$ & $0.035 * * *$ \\
\hline Have seen a dentist & & $0.024 * * *$ & $0.021 * * *$ & & $0.065^{* * *}$ & $0.061 * * *$ & & $0.012 * * *$ & $0.012 * * *$ \\
\hline Country fixed effects & Yes & Yes & Yes & Yes & Yes & Yes & Yes & Yes & Yes \\
\hline
\end{tabular}

Data: Preliminary SHARE wave 8 release 0 . Conclusions are preliminary. Sample: $N=31,819$ respondents in 26 countries

(Unweighted) models including all countries; average marginal effects displayed; * $p$-value $<0.1 * * p$-value $<0.05 * * * p$-value $<0.01$

positively correlated with the likelihood of reporting having faced barriers in accessing care during the pandemic. This result suggests that the healthcare demand during the pandemic was correlated with initial healthcare habits for a given health status, which reflects preferences regarding health and healthcare and initial difficulties in accessing health services.

Notably, the sign of the effect of age on unmet needs changed after controlling for the pre-epidemic differences in care needs and utilisation between respondents: this suggests 
that healthcare needs and utilisation are strongly and positively correlated with age. After "step 2", the probability of having had unmet needs during the first epidemic wave was much lower among the eldest individuals than among those aged between 50 and 64 years for each indicator.

After controlling for baseline differences in healthcare needs and utilisation between individuals (step 2), the overall effects of economic vulnerability on the three measures of unmet needs slightly decreased but did not significantly change compared to those obtained previously in step 1 . This may be explained by two reverse effects: economically vulnerable individuals may have higher pre-epidemic needs than others, on average, but a lower utilisation of care for the same needs. In the end, these two competing effects on unmet needs would tend to cancel each other out.

The full model is finally obtained after controlling for differences in education level and income quartiles (step 3). Having a primary rather than a post-secondary level of education significantly reduces the risk of forgoing care due to fear of COVID-19 by 3.1 percentage points and the risk of having had care postponed by 3.7 points. The former could be partly explained by an underestimation of the risk associated with COVID-19 among the less educated and their difficulties dealing with public health recommendations regarding both the "stay-at-home" policies and the healthcare pathways to be followed during the epidemic.

These effects could also point to social differences in the type and urgency of care used, with care received by the less educated potentially being the most urgent. Education does not have any significant effect on the failure to obtain a medical appointment. The effect of income quartiles on unmet healthcare needs is neither strongly significant nor distributed along a clear gradient. Based on the full model, the magnitude of the effect of economic vulnerability was +1.5 points for forgoing care due to fear of COVID- $19,+0.7$ points for the unavailability of medical appointments and not significant for the probability of having planned care postponed. These effects are remarkably consistent, regardless of whether or not the models are controlled for income quartiles and education level: the variable of economic vulnerability therefore measures a robust specific effect on access to care during this exceptional health situation.

\section{Country-specific impact of economic vulnerability on unmet needs}

The full specification model was then re-estimated on a country-by-country basis to determine the heterogeneous influence of economic vulnerability on access to care across Europe (see Tables ST1, ST2 and ST3 in supplementary material).

Although the effect of economic vulnerability on having forgone medical treatment for fear of infection was significantly positive in the analysis including all countries, it varied substantially among countries (Fig. 1). The risk of forgoing care was higher among the most economically vulnerable individuals in Israel (+12.3 percentage points), the Czech Republic (+8.4) and Sweden (+6.7). This was not true everywhere: in Spain ( -2.9 points), Switzerland (-3.9) and Bulgaria (-4.1), the most economically vulnerable people refrained from accessing medical care for fear of COVID-19 less frequently than others.

A similar pattern was identified in the postponement of medical treatments during the first wave of the epidemic (Fig. 2). The non-significant impact of economic vulnerability on the probability of having had care postponed in the sample including all countries masked the heterogeneous effects across European countries: this particular risk affected economically vulnerable people more frequently than others in France $(+9.4$ points), Denmark $(+9.0)$, the Netherlands $(+6.6)$ and Slovakia $(+5.8)$, while it affected them significantly less in a few other countries, particularly Italy (- 7.5 points) or Malta $(-8.4)$.

The positive effect of economic vulnerability on the unavailability of care was weaker than its effect on forgoing care for fear of COVID-19 in the sample including all countries and was also more uniform across countries (Fig. 3). The most economically vulnerable faced more difficulties obtaining medical appointments or treatments in Spain $(+4.6$ points), while they appeared to experience fewer difficulties in Italy (-3.4).

The interpretation of these country-level differences is not straightforward. Social differences in forgoing care for fear of COVID-19 may be more important in countries in which the most economically vulnerable have been more likely to be exposed to the virus, and the variations in the risk of exposure are themselves potentially correlated with the heterogeneous spread across and within countries between the more and less privileged areas (Northern versus Southern Italy, Catalunya versus other Spanish provinces, Paris versus other French regions). They could also be explained by country-level differences in the type and strictness of social distancing policies and the link between economic vulnerability and attitudes towards risk, which may be related to the generosity of social protection policies. Social differences in postponement and unavailability of care may be more related to country-level variations in the magnitude of healthcare restrictions and the types of care that have been cancelled (GPs versus specialists, public versus private sector, etc.).

The international differences observed during the first wave of the epidemic do not seem to overlap with the established evidence regarding the level of social inequalities in healthcare use and unmet needs across European countries. For instance, the impact of economic vulnerability on unmet needs due to care postponement and the unavailability of care was significantly negative in Italy, although Italy is well 


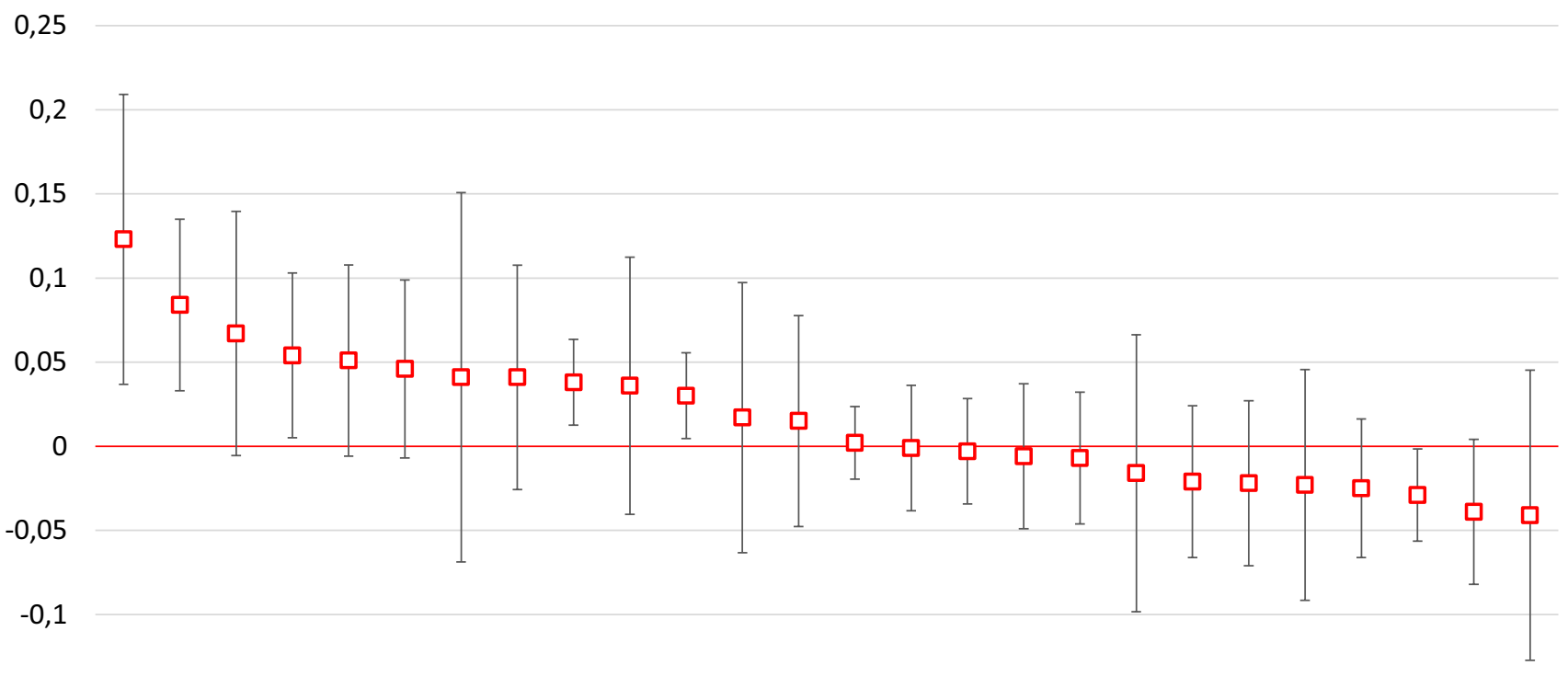

$-0,15$

$-0,2$

$-0,25$

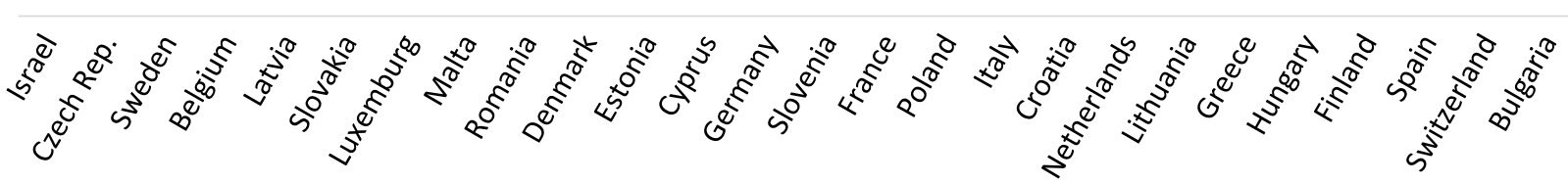

How to read: In Israel, being economically vulnerable has increased the probability of having forgone medical treatment for fear of COVID-19 by 12.3 percentage points, all other things being equal.

Data: Preliminary SHARE wave 8 release 0. Conclusions are preliminary. Sample: $N=31,819$ respondents in 26 countries.

Notes: Full models were estimated country by country; the error bars represent 95\% confidence intervals. The results are expressed as average marginal effects (AME).

Fig. 1 Probability of having forgone medical treatment for fear of COVID-19: effect of economic vulnerability by country (full model)

known for its high level of social inequality with regard to visits to GPs and specialists and unmet needs due to cost, waiting time or distance (OECD, 2019). Conversely, highly positive effects were observed in Spain for unmet needs due to unavailability of care, although the magnitudes of social inequalities in access to care in Spain and Italy are similar. The health systems in both countries can also be considered similar in many aspects, and they both had to deal with a particularly deadly first wave of the epidemic.

In France and Slovakia, larger positive impacts of economic vulnerability on unmet needs due to postponement of care during the pandemic were observed. They are consistent with the greater social inequalities in unmet needs because of cost (Slovakia) and the greater inequalities in specialist care, which is more usually planned (France). In Greece, the positive effect of economic vulnerability on unmet needs due to the unavailability of care is consistent with the existence of social inequality in access to GPs before the pandemic.

\section{Cumulative effects of economic vulnerability and baseline health status on unmet needs}

The final stage consisted of re-estimating the full model over the entire sample by adding an interaction term between economic vulnerability and self-reported health status at baseline (see Table ST4 in supplementary material).

For each of the three types of unmet needs considered, the effect of economic vulnerability was significantly higher (at the $10 \%$ level for postponed care and care unavailable; at the $1 \%$ level for forgone care) among individuals reporting "poor" health before the epidemic than among those reporting "excellent or very good" health 


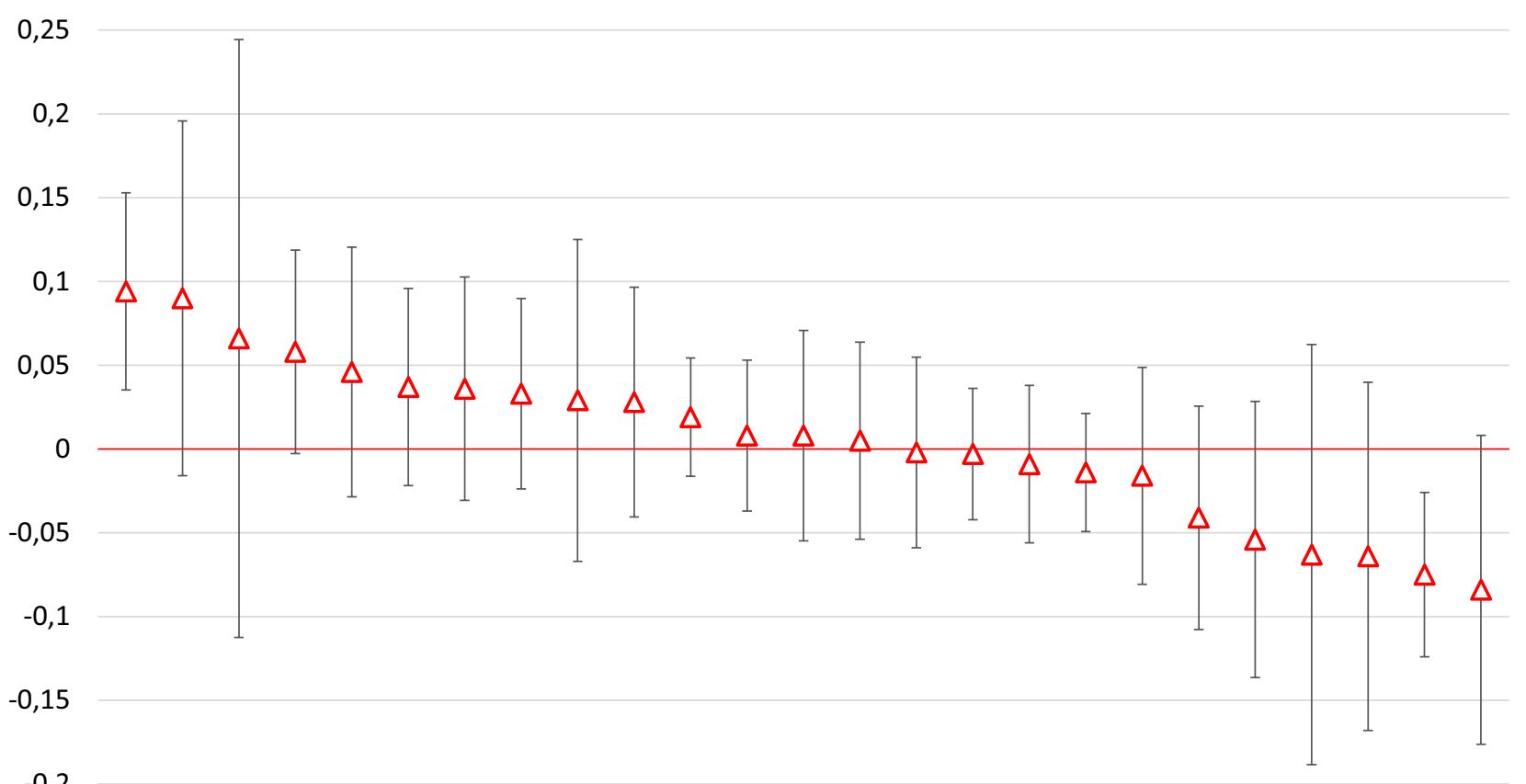

$-0,2$

$-0,25$

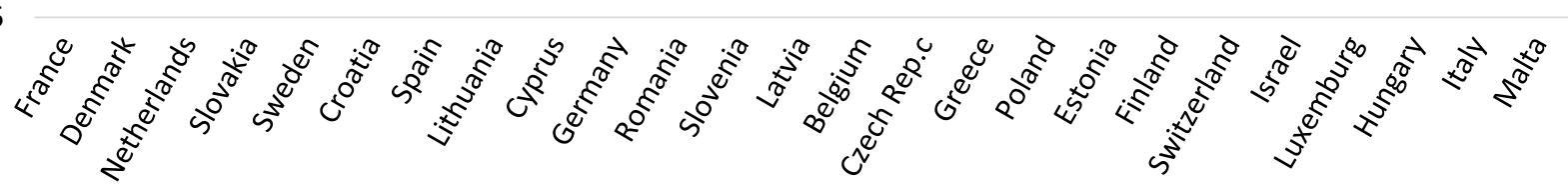

How to read: In France, being economically vulnerable has increased the probability of having had planned medical care postponed by 9.4 percentage points, all other things being equal.

Data: Preliminary SHARE wave 8 release 0. Conclusions are preliminary. Sample: $N=31,219$ respondents in 25 countries.

Notes: Full models were estimated country by country; BG was excluded (too few individuals had a medical appointment postponed); the error bars represent $95 \%$ confidence intervals. The results are expressed as average marginal effects (AME).

Fig. 2 Probability of having had planned medical care postponed: effect of economic vulnerability by country (full model)

(Fig. 4). Among the former, the most economically vulnerable were much more likely than others to have experienced the postponement of planned care ( +4.2 points), for example. Similarly, among individuals reporting "poor" health before the epidemic, those in situations of economic vulnerability were more likely to forgo care for fear of COVID-19 (+3.8), whereas the reverse was true among those with "excellent or very good" health $(-1.9)$. These results seem to suggest that difficulties and barriers to accessing care related to economic vulnerability during the first wave were higher for those with the poorest health status. As a result, the pandemic may ultimately lead to increased health losses for people who suffer both health and economic vulnerabilities.

\section{Discussion}

The aim of this work was to investigate the effect of economic vulnerability on unmet healthcare needs during the first wave of the COVID-19 epidemic among older European adults.

Postponing planned care (25\%) and forgoing healthcare for fear of infection (12\%) were greater obstacles to accessing care for people over the age of 50 years than were difficulties in obtaining medical treatments due to the unavailability of health providers (5\%). Barriers to accessing care had greater effects on those who had the highest need and who used healthcare the most before the outbreak, particularly the oldest individuals. After adjusting for age, sex, relationship status, country, education, income quartile and healthcare needs and utilisation before the pandemic, 


\section{0,25}

0,2

0,15

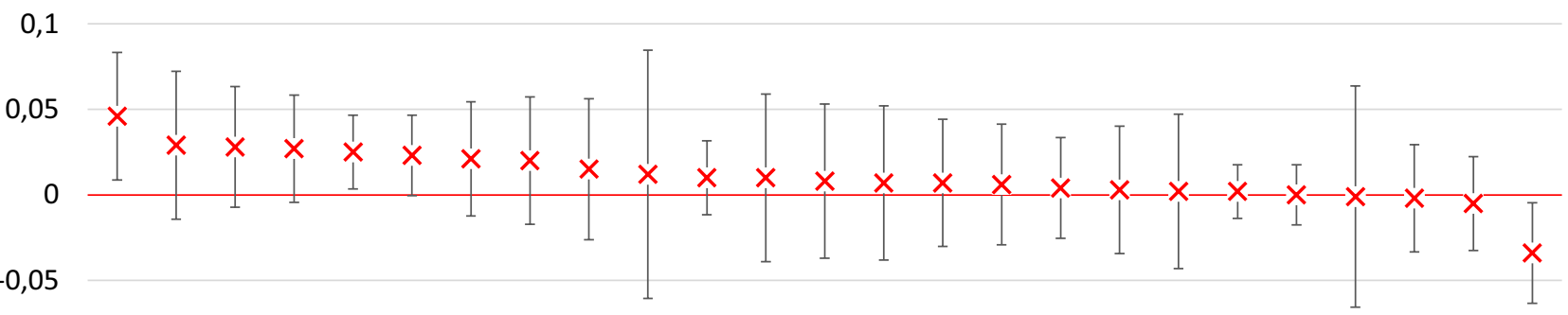

$-0,1$

$-0,15$

$-0,25$

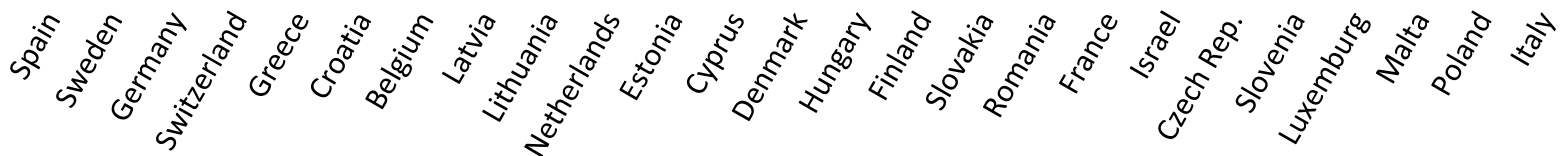

How to read: In Spain, being economically vulnerable has increased the probability of having been unable to obtain a medical appointment or treatment by 4.6 percentage points, all other things being equal.

Data: Preliminary SHARE wave 8 release 0. Conclusions are preliminary. Sample: $N=31,219$ respondents in 25 countries.

Notes: Full models were estimated country by country; $B G$ was excluded (too few individuals unable to obtain an appointment or a treatment); the error bars represent $95 \%$ confidence intervals. The results are expressed as average marginal effects (AME).

Fig. 3 Probability of having been unable to obtain a medical appointment/treatment: effect of economic vulnerability, by country (full model)

economically vulnerable individuals had an additional $1.5 \%$ risk of forgoing care for fear of contracting COVID-19 and an additional $0.7 \%$ risk of being unable to obtain a medical appointment when needed but did not have a significantly higher risk of experiencing care postponement.

The increased risk of forgoing care for fear of COVID19 among the most economically vulnerable may be related to their financial and general insecurity, which may have increased during the pandemic crisis and may have stressed their general feeling of insecurity. In addition, this result may reflect differences in the degree of risk aversion between the less well-off and the well-off (Barsky et al. 1997).

Several factors may explain the higher probability of having tried unsuccessfully to obtain a medical appointment among the most economically vulnerable, even after controlling for their pre-pandemic care needs and utilisation, income quartile and education level. The most vulnerable individuals may have been more discouraged by the difficulties caused by care rationing and the complexity of the steps that were necessary to obtain an appointment. Restrictions and shortages may have been more substantial for certain types of care that are more often used by the most vulnerable population, such as hospital care or care delivered by public sector doctors. On the other hand, the deferral of previously scheduled care seems to have occurred more equally, with no observable difference according to the socio-economic status of the patients.

The effect of economic vulnerability on unmet needs emerged more distinctly among people initially in poor health for all three types of unmet needs. Among those in poor health at baseline, the economically vulnerable had a 4.2-points greater likelihood of experiencing the postponement of scheduled care, a 3.8-points greater likelihood of 


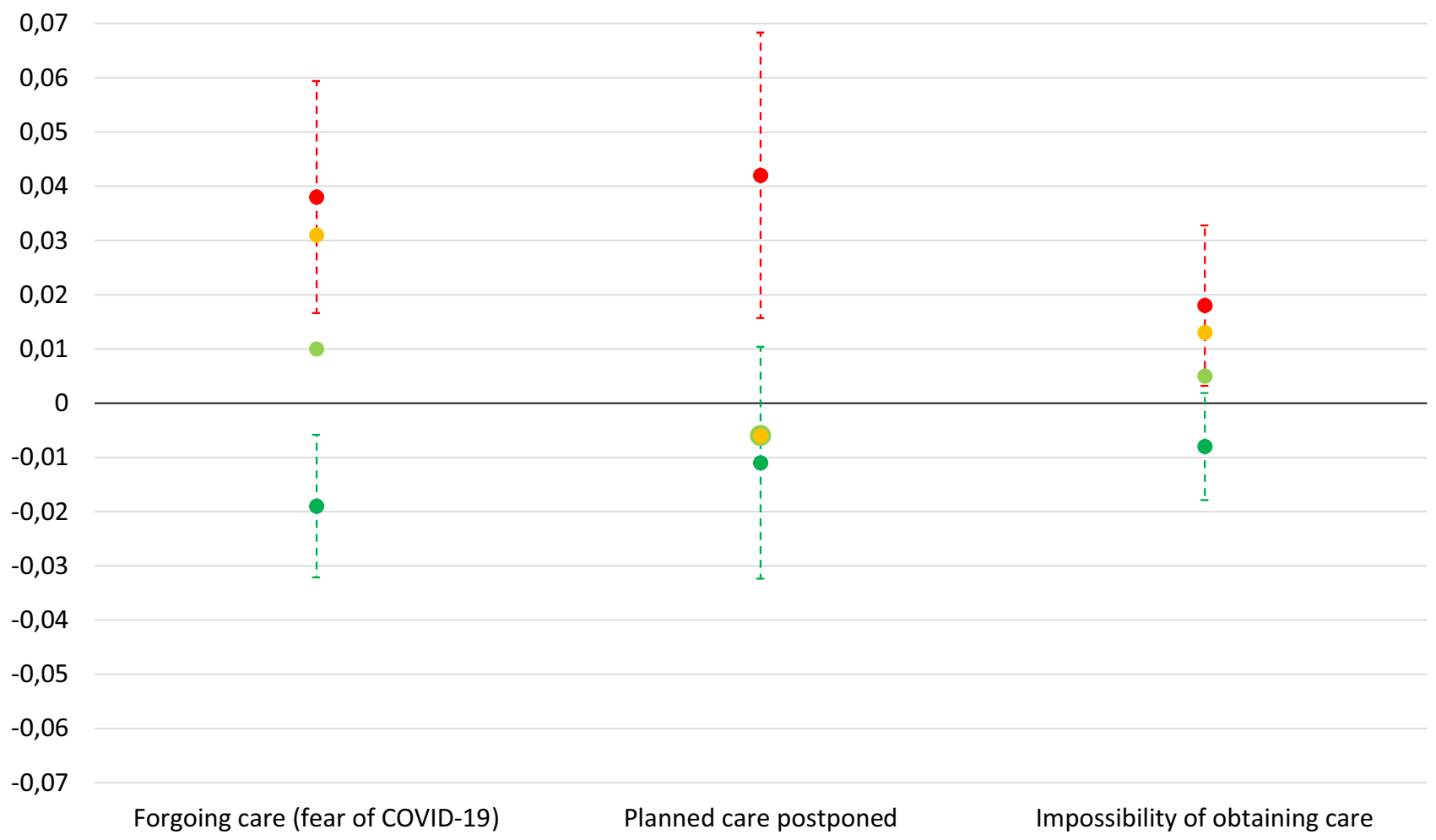

SAH: Excellent or very good $\quad$ SAH : good $\bigcirc \mathrm{SAH}:$ Fair $\quad \mathrm{SAH}:$ Poor

How to read: Among individuals reporting "poor" health before the epidemic, being economically vulnerable has increased the probability of having forgone care for fear of COVID-19 by 3.8 percentage points, all other things being equal.

Data: Preliminary SHARE wave 8 release 0. Conclusions are preliminary. Sample: $N=31,819$ respondents in 26 countries.

Notes: Full models including all countries. The results are expressed as average marginal effects at representative values (AMER), the baseline self-assessed health (SAH) being set to a given particular value. The error bars represent $90 \%$ confidence intervals for SAH being set to "Excellent or very good" and "Poor" respectively.

Fig. 4 Effects of economic vulnerability on unmet healthcare needs according to baseline self-assessed health (all countries)

forgoing care for fear of COVID-19 and a 1.8-point greater likelihood of being unable to obtain a medical appointment. Thus, the reorganisation of health systems caused by the pandemic did not result in a prioritisation of care based exclusively on needs and health status criteria, as difficulties in accessing healthcare for economically vulnerable individuals are mostly observed among the sickest populations.

The impact of economic vulnerability on unmet needs differed substantially among countries, with a notably low impact of economic vulnerability on the postponement of care and the unavailability of new appointments in Italy. The magnitude of the impact of economic vulnerability on unmet needs does not appear to be greater in the countries with the highest initial levels of social inequality in access to care or unmet needs. This finding should be examined in future research to shed light on the differences in social inequalities in access to care during the pandemic according to the organisation of health systems and the various strategies used to confront the pandemic in each country. 
To some degree, the SHARE Corona survey, an innovative approach produced in a very short time frame to respond to this exceptional pandemic, can be subject to selection bias arising from methodological and technical factors. The willingness to participate may also have differed according to age, health, socio-economic status and, particularly, economic vulnerability. To date, there is no empirical evidence of systematic socio-economic participation or attrition bias in SHARE surveys. In addition, the questions used in this survey to measure unmet needs during the pandemic had never been tested before: it is unclear exactly how respondents understood these. The measurement of health also relied on the list of chronic diseases provided by SHARE, which, however broad, does not cover all chronic or acute conditions.

Despite these limitations, this work highlights the risk that these periods of care rationing may ultimately lead to an aggravation of difficulties in accessing healthcare and potential subsequent health deterioration for the poorest. Data from the second wave of the SHARE Corona Survey will be valuable for studying the potential effects of unmet care needs on equity in healthcare in the long term.

Supplementary Information The online version contains supplementary material available at https://doi.org/10.1007/s10433-021-00645-3.

Acknowledgements This publication is based on preliminary SHARE Wave 8 release 0 data (Börsch-Supan 2020). Therefore, the analyses, conclusions and results are preliminary. Please see Scherpenzeel et al. (2020) for methodological details. In addition, this paper uses data from SHARE Waves 1, 2, 3, 4, 5, 6 and 7(DOIs: 10.6103/SHARE.w1.710, 10.6103/SHARE.w2.710, 10.6103/SHARE.w3.710, 10.6103/SHARE. w4.710, 10.6103/SHARE.w5.710, 10.6103/SHARE.w6.710, 10.6103/ SHARE.w7.710); see Börsch-Supan et al. (2013) for methodological details. The SHARE data collection has been funded by the European Commission through FP5 (QLK6-CT-2001-00360), FP6 (SHARE-I3: RII-CT-2006-062193, COMPARE: CIT5-CT-2005-028857, SHARELIFE: CIT4-CT-2006-028812), FP7 (SHARE-PREP: GA N²11909, SHARE-LEAP: GA N ${ }^{\circ} 227822$, SHARE M4: GA N²61982, DASISH: GA N ${ }^{\circ} 283646$ ) and Horizon 2020 (SHARE-DEV3: GA N ${ }^{\circ} 676536$, SHARE-COHESION: GA N ${ }^{\circ} 870628$ SERISS: GA N ${ }^{\circ} 654221$, SSHOC: GA N²23782, SHARE-COVID19: GA N$\left.{ }^{\circ} 101015924\right)$ and by DG Employment, Social Affairs \& Inclusion. Additional funding from the German Ministry of Education and Research, the Max Planck Society for the Advancement of Science, the US National Institute on Aging (U01_AG09740-13S2, P01_AG005842, P01_AG08291, P30_AG12815, R21_AG025169, Y1-AG-4553-01, IAG_BSR06-11, OGHA_04-064, HHSN271201300071C) and from various national funding sources is gratefully acknowledged (see www.share-project. org).

\section{References}

Allin S, Grignon M, Le Grand J (2010) Subjective unmet need and utilization of healthcare services in Canada: what are the equity implications? Soc Sci Med 70(3):465-472. https://doi.org/10. 1016/j.socscimed.2009.10.027
Andersen A (1995) Revisiting the behavioral model and access to medical care: does it matter? J Health Soc Behav 36(1):1-10

Barsky RB, Juster FT, Kimball MS, Shapiro MD (1997) Preference parameters and behavioural heterogeneity: an experimental approach in the health and retirement study. Q J Econ 112(2):537-579

Bertier M, Luyten J, Tubeuf S (2021) Renoncement aux soins médicaux et confinement: les enseignements d'une enquête en ligne. Regards Economiques, Université Catholique de Louvain, 162

Börsch-Supan A, Brandt M, Hunkler C, Kneip T, Korbmacher J, Malter F, Schaan B, Stuck S, Zuber S (2013) Data resource profile the survey of health, ageing and retirement in Europe (SHARE). Int J Epidemiol. https://doi.org/10.1093/ije/dyt088

Börsch-Supan A (2020) Survey of health ageing and retirement in Europe (SHARE) wave 8. Release version: 0. SHARE-ERIC. Preliminary data set

Chatterji P, Li Y (2020) Effects of the Covid-19 pandemic on outpatient providers in the US. National Bureau of Economic Research (NBER), Working Paper Series, No. 27173

CNAMTS (2020) L'actualité en quelques chiffres : les remboursements de soins du régime général à fin avril 2020

Czeisler ME, Marynak K, Clarke KEN, Salah Z, Shakya I, Thierry JM, et al. (2020). Delay or avoidance of medical care because of COVID-19-related concerns. US Department of Health and Human Services / Centers for Disease Control and Prevention, MMWR (Morbidity and Mortality Weekly Report), 69(36).

Davillas A, Jones AM (2021) Unmet health care need and incomerelated horizontal equity in use of health care during the COVID-19 pandemic. Health Econ. https://doi.org/10.1002/ hec. 4282

De Luca G, Rossetti C (2018) Stata program to compute calibrated weights from scientific use file and additional database. SERISS Report D2:10

DeSalvo KB, Fan VS, McDonell MB, Fihn SD (2005) Predicting mortality and healthcare utilization with a single question. Health Serv Res 40(4):1234-1246

Després C, Dourgnon P, Fantin R, Jusot F (2011a) Healthcare renunciation: a socio-anthropological approach. Questions d'économie de la santé, IRDES, 169

Després C, Dourgnon P, Fantin, Jusot F (2011b) Giving up on health care for economic reasons: an econometric approach. Questions d'économie de la santé, IRDES, 170

Devaux M (2015) Income-related inequalities and inequities in health care services utilisation in 18 selected OECD countries. Eur J Health Econ 16(1):21-33. https://doi.org/10.1007/ s10198-013-0546-4

Dourgnon P, Jusot F, Fantin R (2012) Payer nuit gravement à la santé : une étude de l'impact du renoncement financier aux soins sur l'état de santé. Economie Publique 28-29:123-147

Fahey T (2007) The case for an EU-wide measure of poverty. Eur Sociol Rev 23(1):35-47

Goedhart T, Halberstadt V, Kapteyn A, Van Praag B (1977) The poverty line: concept and measurement. J Hum Resour 12(4):503-520

Gonzalez D, Zuckerman S, Kenney GM, Karpman M (2020) Almost half of adults in families losing work during the pandemic avoided healthcare because of costsor COVID-19 concerns. Urban Institute, Policy brief

Hanna TP, Evans GA, Booth CM (2020) Cancer, COVID-19 and the precautionary principle: prioritizing treatment during a global pandemic. Nat Rev Clin Oncol 17(5):268-270

Hartnett KP, Kite-Powell A, DeVies J, Coletta MA, Boehmer TK, Adjemian J, Gundlapalli AV (2020) Impact of the COVID-19 pandemic on emergency department Visits - United States, January 1, 2019 - May 30, 2020. Centers for Disease Control 
and Prevention (CDC), Morbidity and Mortality Weekly Report (MMWR) 69(23): 699-704

Idler EL, Benyamini Y (1997) Self-rated health and mortality: a review of twenty-seven community studies. J health soc behav 38(1):21-37

Jürges H, Stella L (2019) The social dynamics of unmet need, catastrophic healthcare expenses and satisfaction with health insurance coverage. In: Börsch-Supan A, Bristle J, Andersen-Ranberg K, Brugiavini A, Jusot F, Litwin H, Weber G (eds) Health and socio-economic status over the life course first results from share waves 6 and7. De Gruyter, Berlin

Ko H (2016) Unmet healthcare needs and health status: panel evidence from Korea. Health Policy 120(6):646-653

Kranz AM, Gahlon G, Dick AW, Stein BD (2021) Characteristics of US adults delaying dental care due to the COVID-19 pandemic. JDR Clin Transl Res 6(1):8-14. https://doi.org/10.1177/23800 84420962778

Litwin H, Sapir EV (2009) Forgone healthcare due to cost among older adults in European countries and in Israel. Eur J Ageing 6(3): 167-176

Maringe C, Spicer J, Morris M, Purushotham A, Nolte E, Sullivan R, Aggarwal A (2020) The impact of the COVID-19 pandemic on cancer deaths due to delays in diagnosis in England, UK: a national, population-based, modelling study. Lancet Oncol 21(8): 1023-1034

Marmot M, Bell R (2016) Social inequalities in health: a proper concern of epidemiology. Ann Epidemiol 26(4):238-240

Marmot M, Allen J, Goldblatt P, Herd E, Morrison J (2020) Build Back Fairer: The COVID-19 Marmot Review. The pandemic, socioeconomic and health inequalities in England. Institute of Health Equity, London

Mehrotra A, Chernew M, Linetsky D, Hatch, H, Cutler D (2020) The Impact of the COVID-19 pandemic on outpatient visits: a rebound emerges, Commonwealth Fund, To the Point (blog).

Negopdiev D, Collaborative C, Hoste E (2020) Elective surgery cancellations due to the COVID-19 pandemic: global predictive modelling to inform surgical recovery plans. Br J Surg 107(11):1440-1449

NHS (2020) A\&E Attendances and Emergency Admissions 2020-21. NHS data collection. https://www.england.nhs.uk/statistics/stati stical-work-areas/ae-waiting-times-and-activity/ae-attendancesand-emergency-admissions-2020-21/

Organisation for Economic Cooperation and Development (OECD) (2019). Health for everyone? Social inequalities in health and health systems. OECD Health Policy Studies

Pikoulis E, Solomos Z, Riza E, Puthoopparambil SJ, Pikoulis A, Karamagioli E, Puchner KP (2020) Gathering evidence on the decreased emergency room visits during the coronavirus disease 19 pandemic. Public Health 185:42
Rosenbaum L (2020) Facing Covid-19 in Italy_ethics, logistics, and therapeutics on the epidemic's front line. N Engl J Med 382(20): 1873-1875

Sand G (2021, forthcoming) Fieldwork monitoring and survey participation in the regular eighth wave of SHARE. In: Bergmann M, Börsch-Supan A (Eds.) SHARE Wave 8 Methodology. Munich: MEA, Max Planck Institute for Social Law and Social Policy.

Scherpenzeel A, Axt K, Bergmann M, Douhou S, Oepen A, Sand G, Schuller K, Stuck S, Wagner M, Börsch-Supan A (2020) Collecting survey data among the 50+ population during the COVID-19 outbreak: the survey of health, ageing and retirement in Europe (SHARE). Surv Res Methods 14(2):217-221

Smolić Š, Čipin I, Međimurec P (2021) Access to healthcare for people aged 50+ in Europe during the COVID-19 outbreak. Eur J Ageing. https://doi.org/10.1007/s10433-021-00631-9

Søreide K, Hallet J, Matthews JB, Schnitzbauer AA, Line PD, Lai PBS, The CS (2020) Immediate and long-term impact of the COVID-19 pandemic on delivery of surgical services. Br J Surg 107(10):1250-1261

van Doorslaer E, Koolman X, Jones AM (2004) Explaining incomerelated inequalities in doctor utilisation in Europe. Health Econ 13(7):629-647. https://doi.org/10.1002/hec.919

World Health Organisation (WHO) (2020) Pulse survey on continuity of essential health services during the COVID-19 pandemic: interim report, 27 August 2020. World Health Organization. https://apps.who.int/iris/handle/10665/334048

Williamson EJ, Walker AJ, Bhaskaran K, Bacon S, Bates C, Morton CE, Curtis HJ, Mehrkar A, Evans D, Inglesby P et al (2020) Factors associated with COVID-19-related death using OpenSAFELY. Nature 584(7821):430-436

Zheng Z, Peng F, Xu B, Zhao J, Liu H, Peng J, Li Q, Jiang C, Zhou Y, Liu S, Ye C, Zhang P, Xing Y, Guo H, Tang W (2020) Risk factors of critical \& mortal COVID-19 cases: a systematic literature review and meta-analysis. J Infect 81(2):16-25

Zhou F, Yu T, Du R, Fan G, Liu Y, Liu Z, Xiang J, Wang Y, Song B, Gu X, Guan L, Wei Y, Li H, Wu X, Xu J, Tu S, Zhang Y, Chen $\mathrm{H}$, Cao B (2020) Clinical course and risk factors for mortality of adult inpatients with COVID-19 in Wuhan, China: a retrospective cohort study. Lancet 395(10229):1054-1062

Ziedan E, Simon KI, Wing C (2020) Effects of State COVID-19 closure policy on NON-COVID-19 healthcare utilization. National Bureau of Economic Research (NBER), Working Paper Series, No. 27621

Publisher's Note Springer Nature remains neutral with regard to jurisdictional claims in published maps and institutional affiliations. 